\title{
Falling into a routine: from habits to situated practices
}

\begin{abstract}
In line with the concept of 'nudging' people to change their behaviour, there has been increased attention on habit as a focus for psychologically-based health interventions. It is hoped that behaviours initiated by interventions not only become so regular that they are normalised into people's everyday lives, but that through repetition they may eventually become fixed and habitual. In this paper we draw on people's accounts of participating in a trial designed to encourage greater physical activity, and attend to the ways they describe their engagement with interventions within wider narratives of their everyday lives. In contrast to the idea that habit refers to automatic behaviour cued by external stimuli and governed by unconscious cognitive processes, our study describes how people identify many diverse elements that are felt to have equal significance in achieving a routine. Paradoxically, the sense of stability derives not from exact repetition, but from the ability for an assemblage of elements to be configured slightly differently each time. We consequently argue that attending to the diverse range of contextual elements bracketed off from interventions designed to be tested in trials, and the idea that continuity might emerge from variation, demands a reconceptualisation of the concept of habit adopted within many areas of current health psychology.
\end{abstract}




\section{Introduction}

There has been a shift in recent years away from health interventions which draw solely on deliberative models of behaviour change by emphasising the role of choice and decision-making, to approaches based on so-called dual process theories (Evans, 2003). Although there are now many variations of these, the general premise is that conscious awareness is paralleled by an unconscious and largely uncontrolled set of processes (Kahneman, 2011). One of the most well-known articulations of this is the idea of 'nudging' individuals to behave in certain ways, rather than educating or empowering them, or simply taking control on their behalf (Thaler and Sustein, 2008). Combining behavioural economics with research from psychology, the suggestion is that an intervention might consist of subtly altering the contexts in which people make their own health-related decisions (Marteau et al, 2011). Not only might this be more effective and enduring, but it promises to be a rapid and efficient means to reach an entire population. Unsurprisingly, this has had particular appeal for governments who wish to be seen as responsible and yet still be able to emphasise individual autonomy (i).

In line with this, there has been increased interest in linking such interventions with theories of habit, to either disrupt existing 'bad' habitual behaviours (Jager, 2003) or promote and establish new ones (Lally et al, 2010). Part of this shift may be due to an on-going frustration with the apparent disjunction between people's values and actions (Godin, Conner $\&$ Sheeran, 2005), or alternatively the so-called 'gap' between knowledge and attitudes, and ultimate behaviour (Ajzen \& Fishbein 1977). In this way it is hoped that new patterns of behaviour initiated or averted by carefully designed interventions can become so regular that they are normalised into people's everyday lives (Neal et al, 2006). According to the standard psychological approach, actions which initially are consciously appraised can eventually become 'instinctual' 
or 'automatic' once ties with the external world become cemented (Verplanken \& Orbell, 2003; Sutton, 1994), even if initial rewards for behaving in a certain way are no longer recognised (Ouellette $\&$ Wood, 1998). In this way, the health psychology literature presents habits both as obstacles and facilitators of better health.

Ostensibly these debates suggest that health psychology is willingly rescinding its traditional dedication to a rational model of human decision-making, and becoming more aligned to the sociological view on human activity as arising from the interactions between structure and agency, conscious behaviour and engrained learning. However, what is of interest to us is how the boundary between individuals consciously making decisions about their own behaviour (which has been the stalwart of health education programmes for decades) and the recent interest in socalled automatic and habitual behaviour is played out in the field of intervention research, and the extent to which the individual remains the sole focus for these revised models of behaviour. Key to this is the fact that these theories reflect implicit commitments to the nature of individuals and how they relate to their surroundings. In this dichotomised representation, either cognitive processes need to be reflective in order to respond to a changeable environment, or, if the environment stays sufficiently unchanging, they inevitably become automatic. In being presented in this way, individual and environment are constituted in a causal relationship with each other, aligning, in a very practical way, with the kinds of research questions and intervention designs that can then be tested within a trial paradigm.

In a proposed sociological framework of habit, Southerton argues that because the term is so often used synonymously with routine they can justifiably be grouped together. He proposes instead that, in combination, they can be divided according to dispositions, procedures and sequences, since these three dimensions in combination not only determine how specific practices are performed, but also how 
different experiential temporalities thereby arise (Southerton, 2013). However, rather than engage with the applicability of this theoretical classification, here we are more interested in drawing on an empirical example to explore the way health psychology's notion of habit, which underlies the aspirations of a behavioural intervention, contrasts with how people reflect on their everyday, and often mundane, activities. In this way, rather than attempt to define what a habit is we are interested in how the idea is variously used. This paper consequently focuses on the construction of habit as a particular object in a model designed to be trialable. Whilst there is a growing trend for more flexible, adaptive and ecological approaches to interventions more generally (Glass \& McAtee, 2006; Pawson \& Tilley, 1997), much health psychology still strives to emulate classic RCTs which continue to stand as the best method to establish clinical evidence (Bonell et al, 2012). Such an approach is based on the simple experimental logic that in order to test for the changes in one thing, all other things must to be kept stable. But as a consequence, adopting such a model in order to evaluate behavioural interventions not only reproduces the distinction between what is internal and what is external, but actively rejects the possibility that, in practice, these categories may be much more contingent upon each other.

Bennet (2013), taking a Foucauldian approach, argues that the dominant psychological conception of habit has historically been used to inform notions of personhood, and hence been a tool of governmentality by actively constructing and demarcating types of activity and groups of people. Because habits are viewed as that which links humans to other animals, yet can also demonstrate learning and the acquisition of culture, the term represents a middle-ground both between what is thought of as inherited or acquired, and between conceptions of free will and ideas of determinism. We draw on this idea that habit frequently serves as a middle ground, and focus on the kind of boundary work it is often enlisted to do in current health behaviour trials. Here, we would suggest, the issues are not merely around what may 
be learnt and deliberated, but also what constitutes legitimate ground - theoretically, politically, and ethically - for interventions designed not only to improve the health of individuals but also address health concerns at the state level.

Our starting point is a broad and growing body of work that contests models of human behaviour which are regarded as overly deterministic and individualised (Ortner, 1984). Taylor (1995) summarises such positions by highlighting three significant weaknesses with the psychological construction of habit; first, that it is located within the individual as a largely black-boxed intermediary between stimulus and response; second, the context, or 'background', is relegated to anything that is not 'in the head', and is important only in so far as it acts as a cue; and finally, the specific characteristics of individual acts are of no particular relevance. However, as Camic points out (1996), alternative conceptualisations of habit which have only partially been taken up by sociology, frequently find inspiration in some of the early $20^{\text {th }}$ century psychological and pragmatist enquiries prior to the domination of the experimental method - for example, in the work of James (1890; 1914), Dewey (1922) and Mead (1934). In such texts not only is there a greater emphasis on introspection, but there is also less of a definitive separation between 'person' and 'context'. What might be assumed to be the background is presented as actively shaping understanding and appraisal, even if people are not usually aware of it (see also Schatski, 2008). This not only suggests such processes are more complex and creative than any variation of a reflex model might suggest (Joas, 1996), but are inherently embodied and distributed in the world. In other words, corporeal and environmental factors do not merely provide the setting for an individual's behaviour, but intimately constitute it (Shove et al, 2012).

In a parallel discussion, Mol has drawn on Actor Network Theory in an approach she terms 'praxiology' - one that situates practices in a flat network of heterogeneous 
actors (Mol, 2002). Key tenets of this perspective are that one should not privilege the human over the non-human (and hence not assume which actors in a network are more significant than others), and that realities are enacted through very specific, local, configurations of those heterogeneous actors. As a result, the usefulness of the concept of habit demands reassessment since, counter to an apparently commonsense view, the stable repetition of practices should not be attributed to the person over and above other agents. Further, the move from modelling relationships as causal to describing them as two-way exchanges not only demands that the distinction between the individual and the environment is revised, but also reassessing what we take to be 'lived experience' and 'the body'. The point is that experiences may well be continually embodied or inscribed, but the qualities of those experiences are themselves a consequence of the specific nature of the body (Engman \& Cranford, 2016). By emphasising the flows of interaction and communication between a person and their environment, the material body is never a static entity, but is one that is alive to being affected and reconstituted (Blackman, 2008). In this way, for example, Bourdieu's notion of habitus as a set of acquired dispositions refers not only to the internalisation of the external, but crucially, the externalisation of the internal (Wacquant, 2011).

By accepting the inescapable variability of events, and ensuring accounts do not present humans over and above other actors, potentially shifts habit from being something possessed by a person and located 'in the head', to a quality of certain events that arise from the interactions of a heterogeneous set of actors. We adopt this as an analytical starting point to interpret accounts of people participating in a behaviour-change trial. We describe how people adopted the interventions and fashioned them to become part of their everyday routines, in contrast with the design of the trial which was designed to stabilise and standardise the intervention. We go on to use the term 'practice assemblage' to foreground how a dynamic set of elements 
are brought together, but do not associate in exactly the same way on each occasion, and suggest that this simple observation clashes with the expectation that through the precise repetition of elements behaviours were more likely to become habitual.

\section{Method}

As a way of exploring these discussions we interviewed thirty people who took part in a randomised controlled UK trial (the "Get Moving" project, see Cooper et al. 2015). Approval was granted by the National Health Service (NHS) Cambridgeshire 2 Research Ethics Committee (Ref. 09/H0308/3). Given the range of health problems relating to physical inactivity, the theory-based trial aimed to evaluate three minimalcontact interventions that might be affordable and scalable. It principally drew from research that suggests physically inactive people are generally unaware that they are inactive (van Sluijs et al, 2007) and from theories of self-regulation, which propose monitoring and feedback encourages people to track their progress towards a goal (Carver \& Scheier, 2001; Ajzen, Timko \& White, 1982) (ii). The interventions were therefore designed to make participants aware of the levels of physical activity they had undertaken, encourage reflection, and as a result, increase their activity. Finally, it was hoped that promoting regular and consistent behaviour would mean it would eventually become habitual.

Just under 500 trial participants were recruited from a local biomedical campus, consisting of a teaching hospital, university departments and research institute. The setting was primarily a practical choice, but led to discussions about how the workplace was increasingly be regarded as a useful site for health interventions (see Commissaris et al, 2016), and also addressed wider calls for improving the health of NHS staff to set an example to patients (Maruthappu, 2016). Participants were 
randomised to one of four arms: self-completion of an activity diary; use of a webbased computer program that provided graphical feedback to support the electronic monitoring of physical activity using a wrist-worn band (reduced intervention); use of a more comprehensive web-based behaviour change program which not only included support for electronic monitoring and feedback but also integrated components of tethered electronic scales, information about calorific content of food, and recipes (full intervention); and finally, the no-intervention control group.

Separate to the main Get Moving project, our study was designed to capture the experiences and understandings of a sample of these participants across the intervention groups. We were interested in the extent to which their accounts reflected the theoretical underpinnings of the study, or if they drew on alternative conceptualisations to those of 'habit' and 'health behaviour'. Ten participants from each of the three intervention arms were interviewed 3-5 weeks after their final assessments. Interviewees were purposefully selected to reflect a wide range of ages (23-63 years old) and consisted of 24 women and six men. These characteristics were broadly similar to the main trial cohort (iii). Given that our interviews focused on how the different interventions were being used and integrated into people's lives, rather the extent to which they were altering behaviour compared to the control group, participants from the latter were not approached for interview.

The semi-structured format followed a broad topic guide that asked about: participant's experience and awareness of their health; diet and activity levels prior to participation; motivation for participation; use of the intervention equipment; how readings from the intervention equipment and health check were interpreted, and if any changes were made as a result; and participants' understandings of health more broadly. An open-ended style established a momentum in the dialogue that encouraged more free-flowing, and therefore less consciously considered, 
descriptions. Lasting between forty minutes and two and a half hours, they were recorded and sent for external transcription. Transcriptions were imported into NVivo 9 for management and coding. Initial descriptive codes drawn from the topic guide were increasingly augmented by more analytical categories as the data was reviewed.

Although acknowledging the obvious limitations of retrospective accounts, we argue that they can nevertheless provide some revealing insights given we were less interested in what people actually did, and more interested in how they came to articulate what they did (Hitchings, 2012). In particular, the narrative nature of the interviews enabled us to explore whether the psychological concepts and general logic of feedback and self-reflection that underlay the study design was either adopted explicitly or implicitly, and the extent to which people's own accounts of physical activity were linked to participation in the study or rather with more general narratives of everyday life.

Three main themes emerged across all the intervention groups: 1 . the extent to which an intervention was adopted and embedded; 2 . the significance of material elements in descriptions of everyday activities; and 3. participants' ideas of routine and regularity. We therefore present combined summaries of these below. However, although a standard tactic in intervention trials is to try and eliminate the influence of apparently extraneous or confounding elements such that the only differences between groups are the different interventions they receive, starting analysis from the participant's own perspective acknowledges not only that each person is radically different, but that an intervention and its influence comes to be constructed very differently as it is engaged with. As a result, the following sections are limited to general themes that were shared between interviews, at the risk of underplaying how varied each account was. 


\section{Adopting the intervention}

Varying reasons were given for participation in the Get Moving trial, illustrating how, from the outset, individuals imagined different ways the trial and the intervention equipment was going to fit in to their lives. These included a general desire to become more active, wanting to assess the amount of activity they already undertook by using monitoring equipment provided by the study, wanting to gain the "free health check" at the end of the study (sometimes because they had particular health concerns, such as a high cholesterol level), or simply because they were sympathetic to the aims of the study and were happy to help. Perhaps unsurprisingly, these different motivations linked to the degree to which people engaged with the intervention they received; for example, those who wanted the final health check were not always as committed to using the equipment as others. But what appeared to be more significant was the degree to which the interventions fitted into what participants already did in their everyday lives. Some described how they were already very aware of health-related activities, such as what they ate and drank, or the amount and type of physical activity they undertook. For these individuals, measuring food intake, weight and exercise was just a enhancement of the things they already tracked and reflected upon. For example, a 29-year-old male clinical PhD student who received the full intervention disclosed that as well as having spreadsheets to monitor his finances and his scores in a particular game he played, he also monitored the time he spent playing music as well as how much physical activity he undertook:

... It's tough to do because I play music for enjoyment and regimenting practice time was the reason that I quit playing violin in the first place, so it's a tough line between... or a tough sort of... to do something that you do for fun in a regimented way. You know, you can't sort of allot, “OK, I'll have 15 minutes of 
fun today." But yeah, so I don't regiment anything as rigidly as I do the exercise and diet. (Interviewee \#17)

Others described how initial enthusiasm during the trial 'kick-started' activities that were then sustained, or how using the intervention equipment to measure specific activities was soon abandoned once they 'knew' how intensive the activity was. Here, the intervention is accorded with limited long-term influence, and instead thought of only as a trigger for a change that the person themselves then took control of. This subtle shift in attribution meant that any increase in physical activity described was often not considered to be enduring unless the person felt that they had consciously chosen it would be. As a 26 year-old female clinical researcher who received the full intervention explains:

Just because at the beginning I was so keen to log everything down and wear the monitor and everything, it got me back into, and it kind of got me back into that routine again and then I was in the routine then regardless of whether I was logging it or not... I think that's what people need actually is just a kick start, something to get them back in. (Interviewee \#4)

A third set of participants described how, prior to the trial, they had had little overt interest in their health or levels of physical activity. They explained that they ate without particularly thinking about its nutritional content, and usually didn't incorporate physical activity into their schedule. For example, a 56-year-old female local counsellor who received the reduced intervention noted, 'I know that for some people counting calories is the be all and end all... [but] I can't live my life like that' (Interview \#23). Amongst these participants, accounts of taking up the intervention were characterised by the sense that it very difficult to 'fit it in', as illustrated by this 
excerpt from an interview with a 60-year-old female administrator who received the diary intervention:

I tried to walk more, didn't always succeed, I found it difficult within the working day to find 15 minutes to do activity, which was, I don't know if we were busier then or whatever but I did find that quite difficult and then by the time I got home and you do the cooking and the whatever housework, then the moment's gone and you think I'm too tired now [laughs] (Interviewee \#13)

Whilst at one level the repeated idea of fitting the intervention in to their lives clearly refers to a sense that some participants just did not have enough time, it is also suggests a more spatial metaphor, in which there just was not enough 'room' to either incorporate the intervention, or additional physical activity, within their everyday practices. A 42-year-old female administrator who received the diary intervention, for example, talked about how she did not set out to go cycling, but instead this was part of getting to work, an action embedded in her day:

I'd rather just fit it in. Anything that can fit in without actually knowing you're doing it, like cycling to work, you know, it's not a big, it's actually quicker to cycle than to get the bus... so actually it works, you know, for practical reasons. But I wouldn't want to take, you know, an hour out of the day and go for a cycle, 'cause I'd think, "Well, that's a bit of a waste of time". (Interviewee \#25)

Statements such as this evoke a world in which the study inevitably competed with existing lives that were already full and over-demanding. Consequently, for all participants, adoption of their intervention was contingent on other elements in their day-to-day lives. Thus, although the logic of an intervention from the study's point of view is that it can 'intervene', and potentially alter, people's everyday activities, 
from the participants' perspective interventions were talked about in terms of the extent to which they could be aligned and even support existing practices. Those that described how interventions were easily adopted emphasised that this was done alongside things they already did already, rather replacing things they already did. For others, however, new elements were less readily incorporated, and the intervention, even if followed, remained external to the everyday patterns of their lives. This is significant; although the study conceives of an intervention as having the potential to change the behaviour of the individual, from the participants' point of view, it is the nature of their existing practices, which includes other people and things, that determines whether or not an intervention is incorporated or not.

\section{The materiality of the intervention}

The physical design of the research equipment, and problems with using it for any extended period of time, were also significant in the extent to which interventions were felt to have become embedded. For example, the intrusive nature of the activity monitors was frequently mentioned. They were meant to be worn on the participants' arms, where a watch might otherwise sit, and were grey, somewhat unwieldy and attached using a bulky Velcro strap; participants stated that these were ugly, that they didn't wear them in the summer when their forearms were exposed and that they were uncomfortable to wear. The response of a 28-year-old female nurse who received the reduced intervention was typical in this respect:

On the wristband, it's not the most attractive thing, I found that probably altered how much I wore it outside work a lot because it's, you know, it's not that attractive. (Interviewee \# 10) 
Others said they looked like electronic tags for offenders and made them feel awkward. While some found it easy to remember to put them on, others found it hard to do so while the recharging process, necessitating a separate charger, was an added complication. Participation across all interventions thereby involved a range of objects and actions to be undertaken regularly; charging, wearing, registering, writing, turning on a computer, downloading information, etc, all of which were necessary before any measurement or feedback - the supposedly 'active ingredients' of the intervention - could be enacted. The specific material form of the equipment often meant that following the procedures of the trial was described as alien and irritating, whether this was because some of the kit was bulky, or simply because the paper diary was easy to lose and forget about.

The graphs, measurements and numbers presented to individuals, like the monitoring equipment itself, were also components of this wider conceptualisation of the intervention. Not only did the style of feedback representation make a difference to understanding, but this also altered the activities individuals then went on to undertake. For example, a 50-year old female nurse discussed how the results displayed were not very meaningful or helpful because she felt the information was fragmented and detached:

...it would be nice to have like a, like a calendar type type of effect, where maybe days I have done exercise it might be a different colour or something... so something that would give me an overall impression of maybe what I'm doing that month, so if it was just a few little small not bars, but colour, if I had some low exercise colours or no colour then I'd know that it would be quite poor, so it's just something to keep an eye on, ... (Interviewee \#24)

In these accounts it is clear that those elements of the trial which were conceived of by the researchers as merely the modes of measurement and recording were 
experienced by the participants as being as much a part of the intervention as the psychological elements around reflecting on feedback or aiming for goals. In reality an intervention can never be separated from the mode by which it is delivered, and hence is always a combination of different objects and practices. The particular form and design, the materiality of each of these elements - whether a printed diary, an electronic device or a visual representation of information - determine how they are interacted with, and thus, the very nature of any practice that might emerge. As such, what ultimately constitutes the intervention not only is more dispersed, but is likely to vary from one participant to another.

It is clear that from this perspective in order for practices to ever become routine a wide range of objects and activities associated with them need to be drawn together and embedded within everyday life. Here, we have illustrated how the material design of specific elements can serve to facilitate, limit or redefine the relationships with other elements. From this perspective, intervention technologies that remain separate and difficult to use are often not adopted because they lack the potential, in their use, to be sufficiently connected with other elements. As such, the description that the wrist-bands were 'ill-fitting' can be extended beyond simply referring to the fact they were uncomfortable to wear, but like much of the other intervention equipment, because their design they didn't have the capacity to 'fit in' to existing everyday practices.

\section{Routines as constituted and semi-stable}

As described in the introduction, the general psychological approach adopted by this trial suggests that through repetition and the gradual association between an environmental cue and behaviour, an automatic habitual disposition might be 
established. But rather than use the word habit, interviewees spontaneously used the term routine in accounts of regular activities that combined both a string of procedures and a great many different elements. Here, the term routine clearly emphasises the nature of activities in the world, rather than psychological processes.

Many talked about the importance of these routines as a means to organise and manage their lives. For example, a 58-year-old female administrator who received the reduced intervention reports:

I mean both my husband and I work, the girls have left home now and we've been living 31 years together so it becomes a routine then and you do everything the same every day more or less which is sterile but that's how it becomes. (Interviewee \#6)

For others, such as a 49-year-old female accountant who received the diary intervention, there was pleasure in the routine itself; 'I like routines anyway, so for me it's a system that works' (Interview \#7). These routines were not thought of as 'automatic' - since people often would describe numerous details and steps associated that comprised them - but neither were they talked about in terms of meticulous planning or thoughtful decision making. Instead, what got called a routine was dependent on the way different activities were 'scooped up' and connected together in a regularised fashion, not through conscious deliberation but simply the connections made by doing various activities one after another. For example, a 52-year-old female administrator linked how much she tended to eat to her role in providing meals for her family:

...we were a family of four but now our children don't live at home anymore... and as a family, you know, you're used to cooking a certain amount 
of food... And I suppose, you know, it's there and I've been, you know, tucking in... (Interviewee \#2).

In this quote, the participant attributes cooking more food than she and her husband might really need to a lifetime of preparing meals for a larger family. Her experience of the intervention to monitor and reduce their food intake, therefore, became linked to this existing meaning-rich practice. Rather than confront it by reducing the amount she cooked, she went on to describe strategies to cope with, and rationalise, her routinized preparation of excess food; buying smaller plates and then freezing what couldn't be plated as one serving.

What is clear is that in their accounts of routines, interviewees invariably included detailed descriptions of their material, social and environmental nature. People would talk about other individuals (such as their friends and relatives), objects (such as sports gear) and more general organisation features (for example, the types of transport involved to facilitate the activity). These factors were not presented as contextual or secondary, but as key and equal elements that ensured a particular action was experienced as routine. Particular practices were repeated regularly only because of the relative stability of sometimes a large and complex network of factors.

Clearly, changes in circumstance can disturb these routines. Participants readily acknowledged that routines were always vulnerable to disruptions, such as holidays, illness, Christmas festivities and other religious celebrations, or simply changes in the seasons. For example, the same 29-year-old male clinical PhD student who was usually very careful about what he consumed and the amount of exercise he undertook reported that going on holiday to visit his family:

[it] just killed the whole routine, because I was home for two or three weeks... all the work that I'd done previously was just awash, basically, after the... after 
the holidays. 'Cause it's tough to... to do anything when, like at holidays (Interviewee \#17)

Similarly, the same 58-year-old female administrator talked about how her weekly tennis game with a friend came to an abrupt end when the friend was no longer available:

I absolutely felt great, it was a really, really nice thing to do. And then she went for training for one of those charity things, and for some reason her training didn't coincide with mine anymore and it stopped and we both said we really miss it but we just haven't managed to get back into the routine of doing it again (Interviewee \#6)

As well as accounts of routines ending, people also described how they thought routines had originally begun. Some respondents felt that trying to do so was, in some sense, contradictory because routines never actually start because of any one single thing. Instead they described how it was always a combination of elements sometimes a 'coincidence' or just 'fluke' - that meant things converged and a routine transpired. As the same 50-year-old female nurse stated, 'I tend to fall into ways of doing things' (Interviewee \#24). This notion of 'falling' into a routine was used by a number of participants. A 34-year-old female doctor who received the reduced intervention talked of her usual exercise routine in a similar way:

...so the same every day, so it'll be thirty minutes activity Monday to Friday in that kind of way in terms of the, you know, quite habitual way, and then at the weekends it would probably be about thirty minutes as well but it wouldn't be as, I wouldn't make a conscious decision to do it, it would just fall into the day, evening, yeah. (Interviewee \# 14) 
Rather than just a turn of phrase, 'falling' into a routine is perhaps an apt description of how such practices emerge, and the experience of ambivalence that people have about their own agency. In contrast to the expectation that health interventions can be designed and delivered according to prescribed ways in which they change behaviour, and that through repetition these have the potential to become habitual, accounts by participants suggest only those assemblages that are sufficiently flexible to change and adaptation ever become familiar and routine. Significantly, therefore, respondents rarely, if ever, conceived of routine in terms of some psychological version of habit.

\section{Discussion}

Our results are drawn from extended accounts provided by trial participants as they recalled activities at particular times and places, with particular people and objects. The rich data led us to resist dividing the 'individual' from the 'context', or the intervention from its mode of delivery, and, as a consequence, the paper refutes conceiving aspects of the external environment as causal, or the antecedents, of internal, cognitive processes. Rather, paying attention to the participants' own reflections of the diverse elements considered to be essential suggests everyday activities are best thought of as dynamic heterogeneous assemblages of people, objects and places. From this perspective, internal psychological processes are not only enabled by other elements, but are contingent upon them, and, as a consequence, any distinction between the categories of what is 'internal' and what is 'external' is blurred.

In addition, the specific nature of the intervention equipment and other material objects clearly shaped their use; although the trialists tended to see the equipment 
simply as a means to deliver the psychologically-informed intervention (or what they sometimes termed the 'active ingredient'), from the participants' point of view the equipment often was the intervention. For some of the participants the trial's interventions had little appeal and failed to become embedded; the equipment and associated practices were experienced as foreign and simply didn't link up with already established routine activities. In contrast to the researchers, who were seeking to establish which might be the most effective of the three interventions, this sense of disconnection was not dependent on the particular form of intervention per se, but rather the relation between the intervention and people's existing practices. In contrast, the interventions were adopted by others if they were experienced as having a degree of affinity with existing practices. Over time, if recurrent practices settled in to a general configuration and are experienced as 'fitting', they sometimes led to the sense that a new routine had emerged, with the person feeling that they 'fell' into it without deliberately trying to do so. As such, they had the potential to be enduring, as long as elements in the new configurations (including the various elements of the intervention) were not altered or withdrawn.

It is worth emphasising that this simple finding is potentially significant because it suggests that, paradoxically, interventions were successful as long as they did not threaten to intervene unduly; rather, what was important was the degree to which they aligned. Many accounts also described how, even when a routine successfully emerged, this could be fragile if there was not sufficient flexibility for elements to respond to the constant variations of living. In combination, this suggests that routine practice assemblages should never be thought of as fixed or stable, but are always in movement; on each occasion, differing iterations drawing together elements in slightly different ways. Equally, foreseeing when an assemblage might be irreconcilably disrupted is inherently unpredictable because it can never be known in advance which elements of an assemblage might be the most significant actors in 
a configuration. The point is that there are different temporalities in these renderings of human practice, and that being able to understand something retrospectively does not mean it is possible to predict events in the future.

We introduced this paper by noting that there has been increased attention on theories of habit to support behaviour change interventions within public health. It is hoped that behaviours initiated by interventions not only become so regular that they are normalised into people's everyday lives, but that if they are sufficiently routinized they may eventually become entrenched and automatic. Because psychological descriptions of habit emphasise the role of an identical environment to cue automatic behaviour, not only is a clear and definite linear causality implied, but there is a central assumption that both habit and behaviour are attributes of the person, presented as separate and detached from their environment. However, by listening to people's own accounts of their everyday activities, what is striking is the extent to which they do not necessarily place themselves as central; many other elements are accorded with just as much, and sometimes more, significance than they themselves.

We suggest that, in people's use of the terms, the ideas of habit and routine refer to subtly different things; while the locus of habit is considered to be the individual, in a routine the primary locus is the specific nature of the activity or practice. This distinction is potentially significant because it points to how people regard their own position in relation to practices that they don't fully feel agents of. We consequently suggest that by shifting the focus from a concern with internal mental processes to an emphasis on the interaction and coordination of different kinds of actors the degree to which an action is experienced as routine or not is derived from a diverse constellation of elements. And substituting the notion of habit with the idea of routine practice assemblies also captures some of the ambivalent qualities in 
participants' own accounts. At times these activities may well be done with little or no awareness - whilst on other occasions, the same person doing the same thing may actually be highly aware of their actions. In this way, what makes a practice routine does not stem from an internal mental state or process, but the stability of the entire assemblage of the many different elements. Further, because routine practices are always situated - that is, are contingent on things within a specific location - they are likely to transform, or can be entirely disrupted, if any one of the contributing elements alters.

Attending to the extensiveness of people's accounts acknowledges not only the active role of elements usually relegated to 'context', but highlights the continual interactions between diverse human and non-human actors. Throughout participants' detailed descriptions, enduring practices were described as being regular but never exact replications; the flow of time and subtle variation of circumstance meant that each occasion was, importantly, also a unique event. This suggests that what is key is that an assemblage always has a degree of flexibility to ensure a routine activity is not too 'brittle'. People thereby presented routines as both resilient and fragile, and that these uncertain qualities were felt to be beyond their own control. In other words, rather than reproducing the researchers' conceptualisation that habit refers to internal and automatic processes, activities that were described as routine were so because of the very ambivalent sense of agency people felt when recalling how many diverse interacting elements were felt to be crucial.

Rather than simply supporting the shift from rational approaches of behaviour change interventions to ones that focus on what is said to constitute more automatic, non-deliberative behaviour - such as nudges and habit formation - we suggest adopting an alternative, dynamic practice-orientated perspective. This entails moving 
away from many of the psychological underpinnings that target the individual, to a perspective that regards both the person and their activities not only as being embedded within a constellation of things, people and other practices, but contingent upon them. This approach challenges the common-sense idea that people are unquestionably the agents of their own activities and that the best strategies to improve health are necessarily interventions conducted on individuals, even if this is across a large population. Such typical interventions are invariably designed to interrupt existing behaviours and relations between elements. Instead, by thinking about practices as local assemblages, the health imperative becomes one of how to encourage certain configurations and ensure that they can become self-sustaining whilst allowing them to also be self-organising. Such an approach presents change and transformation not as the antithesis to continuity, but paradoxically as a means to achieve it (Massumi, 2002). 


\section{Notes}

i Some, however, have argued that it merely masks an ideological commitment to 'neo-liberalism', in which influence and control is exerted more surreptitiously through such things as the market and rhetoric of free choice. (Brown, 2012)

ii Carver and Scheier '...treat behaviour as the consequence of an internal guidance system inherent in the way living beings are organized. The guidance system regulates a quality of experience that's important to it. For that reason, we refer to the guidance process as a system of self-regulation.' (Emphasis in the original) $(2001, \mathrm{p} 3)$

iii Of the 488 participants, $83.5 \%$ women, $16.5 \%$ men, age range: $18-65$ years with a mean of 43 years

\section{References}

Ajzen, I., \& Fishbein, M. (1977). Attitude-behavior relations: A theoretical analysis and review of empirical research. Psychological Bulletin, 84(5), 888-918.

Ajzen, I., Timko, C., \& White, J.B. (1982). Self-monitoring and the attitude-behavior relation. Journal of Personality and Social Psychology, 42(3), 426-435.

Bennet, T. (2013) Habit: Time, freedom, governance. Body \& Society 19 (2-3), $107-$ 135

Bennet, T. et al (2013) Introduction. Special Issue on Habit: Body \& Society June \& September; 19 (2-3)

Blackman, L. (2008) Affect, Relationality and the 'Problem of Personality'. Theory, Culture \& Society 25(1):23-47

Blue, S., Shove, E., Carmona, C. and Kelly, M.P. (2014) Theories of practice and public health: Understanding (un)healthy practices. Critical Public Health, 26 (1), $36-50$

Bonell, C., Fletcher, A., Morton, M., Lorenc, T., \& Moore, L. (2012). Realist randomised controlled trials: a new approach to evaluating complex public health interventions. Social Science \& Medicine, 75(12), 2299-2306.

Brown, P. (2012) A nudge in the right direction? Towards a sociological engagement with libertarian paternalism. Social Policy and Society, 11 (3), 305-317

Camic, C. (1986) The matter of habit. American Journal of Sociology, 91 (5), 10391087

Carver CS, Scheier MF. (2001) On the self-regulation of behavior. New York:

Cambridge University Press 
Commissaris, D., Huysmans, M. Mathiassen, SE, Srinivasan, D., Koppes, LL \& Hendriksen, I (2016). Interventions to reduce sedentary behavior and increase physical activity during productive work: a systematic review. Scandinavian Journal of Work, Environment \& Health, 42(3).

Cooper A., Dearnley K., Williams K.M., Sharp S.J., van Sluijs E.M., Brage S., Sutton S., Griffin S.(2015) Protocol for Get Moving: a randomised controlled trial to assess the effectiveness of three minimal contact interventions to promote fitness and physical activity in working adults. BMC Public Health. 27;15:296. doi: 10.1186/s12889-015-1654-0.

Dewey, J. (1922) Human Nature and Conduct: An introduction to social psychology. New York; Henry Holt \& Company

Engman, A. \& Crnaford, C. (2016) Habit and the body: Lessons for social theories of habit from the experiences of people with physical disabilities. Sociological Theory. 34(1) 27-44

Evans, J. (2003) In two minds: Dual-process accounts of reasoning. TRENDS in Cognitive Sciences, 7 (10), 454-459

Glass, T. A., \& McAtee, M. J. (2006) Behavioral Science at the Crossroads in Public Health: Extending Horizons, Envisioning the Future. Social Science and Medicine, 62(7), 1650-1671

Godin, G., Conner, M., Sheeran, P. (2005). Bridging the intention-behaviour gap: The role of moral norm. British Journal of Social Psychology. 44 (4): 497-512

Haney, C., Banks, W. C., and Zimbardo, P. G. (1973) A study of prisoners and guards in a simulated prison. Naval Research Review, 30, 4-17

Hitchings, R. (2012) People can talk about their practices. Area, 44 (1), 61-67

Jager, W. (2003). Breaking bad habits: a dynamical perspective on habit formation and change. Human Decision-Making and Environmental Perception-Understanding and Assisting Human Decision-Making in Real Life Settings. Libor Amicorum for Charles Vlek, Groningen: University of Groningen.

Joas, H. (1996) The Creativity of Action. Chicago: University of Chicago Press

Kahneman, D. (2011) Thinking Fast and Slow. Penguin Books Ltd; London

Lally, P., Van Jaarsveld, C.H.M., Potts, H.W.W., and Wardle, J. (2010) How habits are formed: Modelling habit formation in the real world. European Journal of Social Psychology, 40, 998-1009

Maller, C.J. (2015) Understanding health through social practices: Performance and materiality in everyday life. Sociology of Health and Ilness, 37 (1), 52-66

Maruthappu, M. (2016) Delivering triple prevention: a health system responsibility. The Lancet Diabetes \& Endocrinology, 4(4):299 - 301 
Massumi, B. (2002) Parables for the Virtual: Movement, Affect, Sensation. Durham: Duke University Press

Marteau, T.M, Ogilvie, D., Roland, M., Shrucke, M., Kelly, M.P. (2011) Judging nudging: can nudging improve population health? British Medical Journal, 342, 263-265

Mol, A. (2002) The body multiple: Ontology in medical practice. Durham: Duke University Press

Neal, D., Wood, W. and Quinn, J.(2006) Habits - a repeated performance. Current Directions in Psychological Science 15(4), 198-202

Ortner, S (1984) Theory in anthropology since the sixties. Comparative Studies in Society and History, 26: 126-166

Ouellette, J. A., and Wood, W. (1998) Habit and intention in everyday life: The multiple processes by which past behavior predicts future behavior. Psychological Bulletin, 124(1), 54-74

Pawson, R. \& Tilley, N. (1997) Realistic evaluation. London; Sage

Schatzki, T. (1996) Social practices: A Wittgensteinian approach to human activity and the social. Cambridge: CUP

Shove, E., Pantzar, M. and Watson, M. (2012) The dynamics of social practice: Everyday life and how it changes. London: Sage

Southerton, D. (2013) Habits, routines and temporalities of consumption: From individual behaviours to the reproduction of everyday practices. Time $\&$ Society, 22 (3), 335-355

Sutton, S. (1994) The past predicts the future: Interpreting behaviour-behaviour relationships in social psychological models of health behaviour. In Rutter, D.R. and Quine, L. (eds) Social Psychology and health: European perspectives. Aldershot: Avebury, pp. $71-88$

Taylor, C. (1995) To follow a rule. In Taylor, C. Philosophical Arguments. Cambridge, Mass.: Harvard University Press, pp.165-80

Thaler, R.H. and Sustein, C.R. (2008) Nudge. Improving decisions about health, wealth and happiness. New Haven and London: Yale University Press

van Sluijs, E.M., Griffin, S.J., van Poppel, M.N. (2007) A cross-sectional study of awareness of physical activity: associations with personal, behavioral and psychosocial factors. International Journal of Behavioral Nutrition and Physical Activity 4:53.

Verplanken, B. and Orbell, S. (2003) Reflections on past behaviour: A self-report index of habit strength. Journal of Applied Social Psychology, 33(6), 1313-1330 
Wacquant, L. (2011) Habitus as Topic and Tool: Reflections on Becoming a Prizefighter. Qualitative Research in Psychology, 8:81-92 